\title{
The Global Nomad: Backpacker Travel in Theory and Practice
}

Edited by Greg Richards and Julie Wilson. Channel View <www.chan-nelviewpublications.com $>2004$, $x i+298$ pp (tables, notes, references, index) \$39.95 Pbk. ISBN 1-873150-76-8

This volume provides a valuable insight into the phenomenon of backpackers in both theoretical and practical perspectives. At the departure point of the book, backpackers - treated as global nomadsare conceptualized mainly in the context of modern and postmodern societal modes of the West. This book will appeal to anyone who is interested in the social phenomena reflected in the form of tourism, and to those who are in the area of tourism with a sociocultural, anthropological, or managerial focus.

The volume is organized into four parts. Acknowledging the growing need to understand this phenomenon, Greg Richards and Julie Wilson open the book by describing the motivations for setting up the Backpacker Research Group and then presenting the findings from a global survey. The study identifies backpackers, destinations visited, motivations and activities, and basic trip characteristics. This investigation reveals that backpackers are a nonhomogeneous group of people despite some seemingly common traits.

Part two opens with Eric Cohen's critical comparison of classic drifters of the 60s/70s with today's backpackers. He draws relationships among tramping, drifters, and present backpackers, pointing out that "the model for the drifter was the tramp, the drifter is the model for the backpacker" (p. 44). He then shows the inherent disparities between ideology and practice of contemporary backpackers, including an examination of the concept of the rite de passage as a heuristic device for understanding backpackers. The current lack of attention to backpackers of different nationalities is further pointed out before the chapter ends with suggestions for future research. 
Irena Ateljevic and Stephen Doorne review the literature in chapter 4. They show that the work by Vogt (1976) and Cohen, 1972, Cohen, 1973, Cohen, 1979 provided the foundation for research on the phenomenon, where an emphasis on freedom and mobility is central. Research exploring internal complexities and external developments emerged in the $80 \mathrm{~s}$ and it is argued that the semantic shift to "the backpacker" reflects a new and coherent market niche. Next, Peter Welk identifies and traces the importance of an anti-tourist attitude as an element of the backpacker. Defining this as a tourist subculture, he argues that mainstream tourism is the opposite side of the same coin, as backpackers do not reflect the whole society but only themselves.

Jana Binder emphasizes the importance of a qualitative approach to understanding the backpacking phenomenon. She echos Cohen's argument as she points out that the emphasis of research on backpacking should be on its dynamic and diverse nature. Darya Maoz examines Israeli backpackers and finds two distinctive patterns. "Conquerors" are aggressive and usually have recently completed their military services and "settlers" are young adults more open to experiencing the environment and less intense in attitudes. Part two closes with Wilson and Richard's look at literary influences on the formation of backpacker identity. They examine iconic travel writers, arguing that backpacking today is better seen as a continuum of sub-ideologies of its own than as a homogeneous phenomenon.

Part three focuses on profiling backpackers in practice. Clare Speed and Tony Harrison examine barriers to the development of the informal backpacking segment in Scotland. Offering an interesting contrast, Lee Slaughter describes the rapid recognition and adaptation of this niche by the tourism industry and government in Australia with detailed identification of backpacker markets 
in the country. Malcolm Cooper, Kieran O'Mahony and Patricia Erfurt trace the Harvest Trail Circuit in Australia, arguing that backpackers are not nomads but stay on the beaten track with respect to employment opportunities in rural areas. Denise Kain and Brian King examine how inbound (to Australia) backpackers gather information and what factors influence their decisionmaking. Suggestions for future research are made along with some implications for supply issues. Part three concludes with two chapters on New Zealand. Ken Newlands profiles backpackers in this country and, like several authors, argues that they do not have homogeneous motivations, activities, and travel styles. Paul Vance applies the conceptual framework of transport choice process to backpackers in New Zealand. The utility of this framework is confirmed even in this relatively small destination.

The final part revisits the issues, notions, and suggestions covered in this volume. Richards and Wilson affirm the symbolic role of backpackers in tourism debates-hence its value for researchers and practitioners-while keeping the nature of their experiences in the center. They argue that "a hybridization of cultures" (p. 255) perhaps best describes the very nature of the nomad syndrome, which is echoed when describing the phenomenon as a state of "suspension" and the backpackers', being satisfied with the notion of "neither here nor there" (p. 257). Aspects of time, space, identity, and "safe danger" as part of their experiences are further detailed before the concluding suggestions for future research.

This volume provides a significant departure point for more systematic and comprehensive research on the backpacker phenomenon. It is clearly laid out and very enjoyable to read. The authors' evident fascination and enthusiasm for their subject will certainly attract more researchers to this important area. Their eagerness for future research activities throughout this volume is one thing that is hard to miss. 
Young-Sook Lee,

Department of Tourism, Leisure Hotel and Sport Management, Griffith University, Gold Coast QLD 9726, Australia. Email <young-sook.lee@ griffith.edu.au>

References

Cohen, $\mathrm{E}$.

1972 Toward a Sociology of International Tourism. Social Research 39:164-182.

1973 Nomads from Affluence: Notes on the Phenomenon of Drifter-Tourism. International Journal of Comparative Sociology 14:89-103.

1979 A phenomenology of Tourist Experiences. Sociology 13:179-201.

Vogt, J.

1976 Wandering: Youth and Travel Behaviour. Annals of Tourism Research 4:25-41. 